\title{
Supramolecular Anion Recognition Mediates One-Pot Synthesis of 3- Amino-[1,2,4]-Triazolo Pyridines from Thiosemicarbazides
}

\author{
Komala Pandurangan, Anna B. Aletti, Devis Montroni, Jonathan. A. Kitchen, Miguel Martínez- \\ Calvo, Salvador Blasco, Thorfinnur Gunnlaugsson* and Eoin M. Scanlan*
}

School of Chemistry, Trinity College Dublin and Trinity Biomedical Science Institute (TBSI), The University of Dublin, Dublin 2, Ireland.

Supporting Information Placeholder

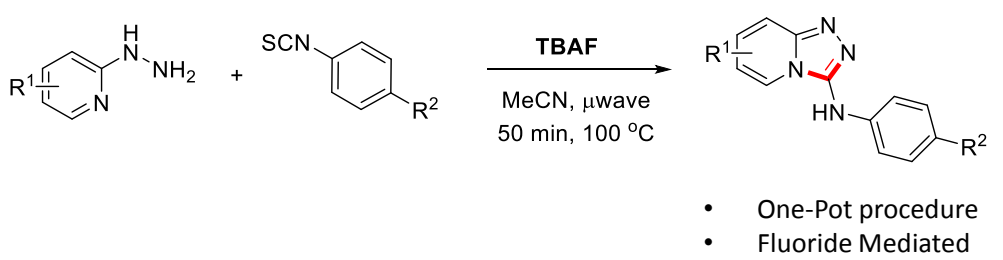

\begin{abstract}
A facile one-pot synthesis of 3-amino-[1,2,4]-triazolo[4,3-a]pyridines from thiosemicarbazides through anion mediated synthesis is reported. Thiosemicarbazides derived from 2-hydrazino pyridine, 5-chloro 2-hydrazino pyridine and 2-hydrazine quinoline were formed in situ as anion receptors in the presence of TBAF. Under microwave heating, thiosemicarbazides furnished the triazolo pyridines in good to moderate yields. The formation of the thiosemicarbazides hydrogen bonding anion receptors was critical in cascading the reaction towards the formation of the triazolo pyridines.
\end{abstract}

Triazolo pyridines are an important class of organic molecules for medicinal chemistry and are associated with a broad range of biological activity., ${ }^{1,2}[1,2,4]$ Triazolo pyridine analogues display potent activity against p38 mitogen activated protein kinase (MAKP); a key enzyme in regulating proinflammatory mediators such as IL1- $\beta$ and TNF- $\alpha$. Selective inhibitors of p3 8 are of therapeutic interest for the treatment of chronic obstructive pulmonary disease (COPD). ${ }^{3}[1,2,4]$ Triazolo pyridine analogues also function as inhibitors of Akt1 and Akt2 kinases involved in the regulation of survival, proliferation and growth of cells, ${ }^{4}$ and of JAK2, a critical target for oncology. ${ }^{5}$ However, detailed investigation into their biological function has been hampered due to limited suitable methodologies for their synthesis. A number of multistep methods have been reported, usually involving highly toxic desulfurizing reagents. ${ }^{6}$ Recently Swinnen and co-workers ${ }^{7}$ reported a synthesis, starting from thiosemicarbazides, using polymer-supported Mukaiyama's reagent. They proposed a reaction mechanism via a highly reactive carbodiimide intermediate that undergoes cyclization to yield the triazolo pyridine core. Herein, we report the synthesis of $3^{-}$ amino-[1,2,4]-triazolo[4,3-a]pyridine analogues (Table 1), starting from 2-hydrazino pyridines in a one-pot synthesis involving tetrabutylammonium fluoride (TBAF) as a reagent $^{8}$. This approach was inspired by our interest in employing supramolecular structures in synthetic chemistry, ${ }^{a-b}$ where in situ formation of thiosemicarbazide based anion receptors is a key step. Hydrogen bonding receptors, such as urea, thioureas, squaramides and amides, are commonly used in supramolecular anion chemistry and in organocatalysis. ${ }^{10,11}$ However, the use of such structures as 'reagents' in organic synthesis is not widely explored; the exception being the use of thiourea in the preparation of guanidinium structures (via thiouronium formation). TBAF is widely employed in organic synthesis as a $\mathrm{F}^{-}$ source and as a mild base. It is known to act as a catalyst for the reduction of aldehydes and ketones using hydrosilanes and also for the chemoselective reduction reactions of phthalimides and imidazolidine-2,4-diones. ${ }^{12} \mathrm{We}$ have used TBAF to activate aryl amines towards converting $\mathrm{CO}_{2}$ to $\mathrm{HCO}_{3}$, via the formation of $\mathrm{HF}_{2}{ }^{-}{ }^{13}$ TBAF is used in fluorine mediated homocoupling of aryl halides ${ }^{14}$ and as a mild base for the elimination reaction of bromoalkenes to alkynes. ${ }^{15}$ Herein we demonstrate that by simply mixing 2-hydrazino pyridines with TBAF and isothiocyanates in a one-pot reaction yields triazolo pyridines under microwave irradiation. 
Thiosemicarbazides recognize anions through hydrogen bonding where significant color changes can occur due to deprotonation of a 'thiourea proton' by basic anions. ${ }^{16-18}$ This was confirmed using NMR spectroscopy and X-ray crystallography. ${ }^{16,24}$ On further investigation, we discovered that treatment with dry TBAF could convert the thiosemicarbazide into a new product upon standing. The reaction mixture yielded crystals suitable for X-ray crystal structure analysis, which showed the successful formation of the $[1,2,4]$ triazolo pyridine product.

In order to investigate the scope, we used three different hydrazinopyridine starting materials, namely 2hydrazinopyridine, 5-chloro-2-hydrazinopyridine and 2hydrazinoquinoline (Table 1). For each substrate, we investigated the TBAF mediated cyclisation reaction with eight different isothiocyanates. Those bearing either electron-withdrawing (EW) and electron-donating (ED) substituent's on the phenyl ring. In the case of 2-hydrazino pyridine, all of the eight isothiocyanates furnished the expected $[1,2,4]$-triazolo[4,3-a]pyridine amine derivatives. Irrespective of the nature of the substituent on the phenyl ring of the isothiocyanate, all of the reactions furnished the desired triazolo pyridines, after 50 minutes of microwave irradiation, at $100{ }^{\circ} \mathrm{C}$. However, it is noteworthy to point out, that the thiosemicarbazides formed in situ from isothiocyanates possessing electron withdrawing substituent, tended to undergo cyclization much more efficiently (e.g. 1-5). In fact, the more electron-rich isothiocyanates (e.g. 6-8) gave substantially lower yields, as summarized in Table 1. For these reactions, the thiosemicarbazide intermediates were obtained in ca. $15-30 \%$ yields upon isolation using automatic $\mathrm{SiO}_{2}$ column chromatography. Because of this drawback, we performed these reactions with increasing $(1.1,2.1,3.1$ and 4.5$)$ equivalents of TBAF, but in general, no significant improvement in yield was observed. Only for the formation of paranitro derivative 1 was there a noticeable enhancement, where the yield of 1 increased from $27 \%$ to $56 \%$ upon using 2.1 equivalents of TBAF.

Following on from the above studies, we extended this methodology to 5-chloro-2-hydrozino pyridine and 2hydrazino quinolone using the same eight isothiocyanate derivatives. The 5-chloro-2-hydrazino pyridines furnished

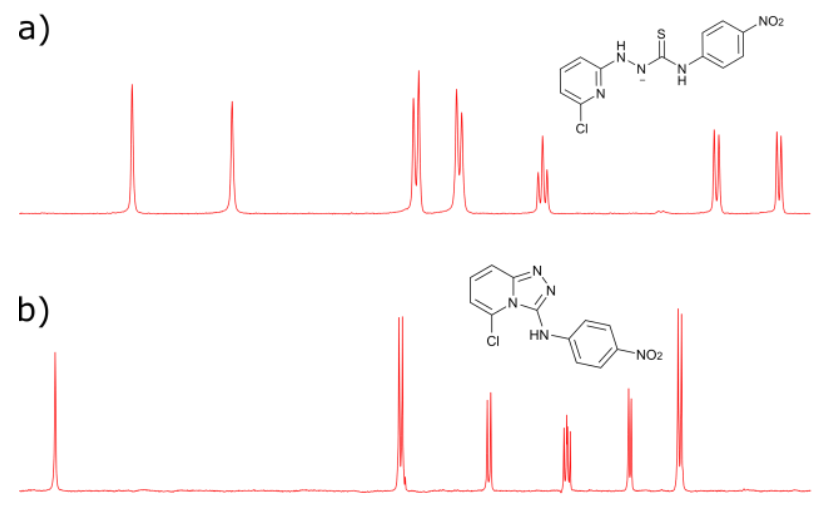

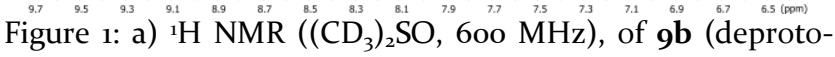
nated) and b) 9.
Table 1: Reaction conditions of 3-amino-1, 2, 4-triazolo[4,3-a]pyridines.

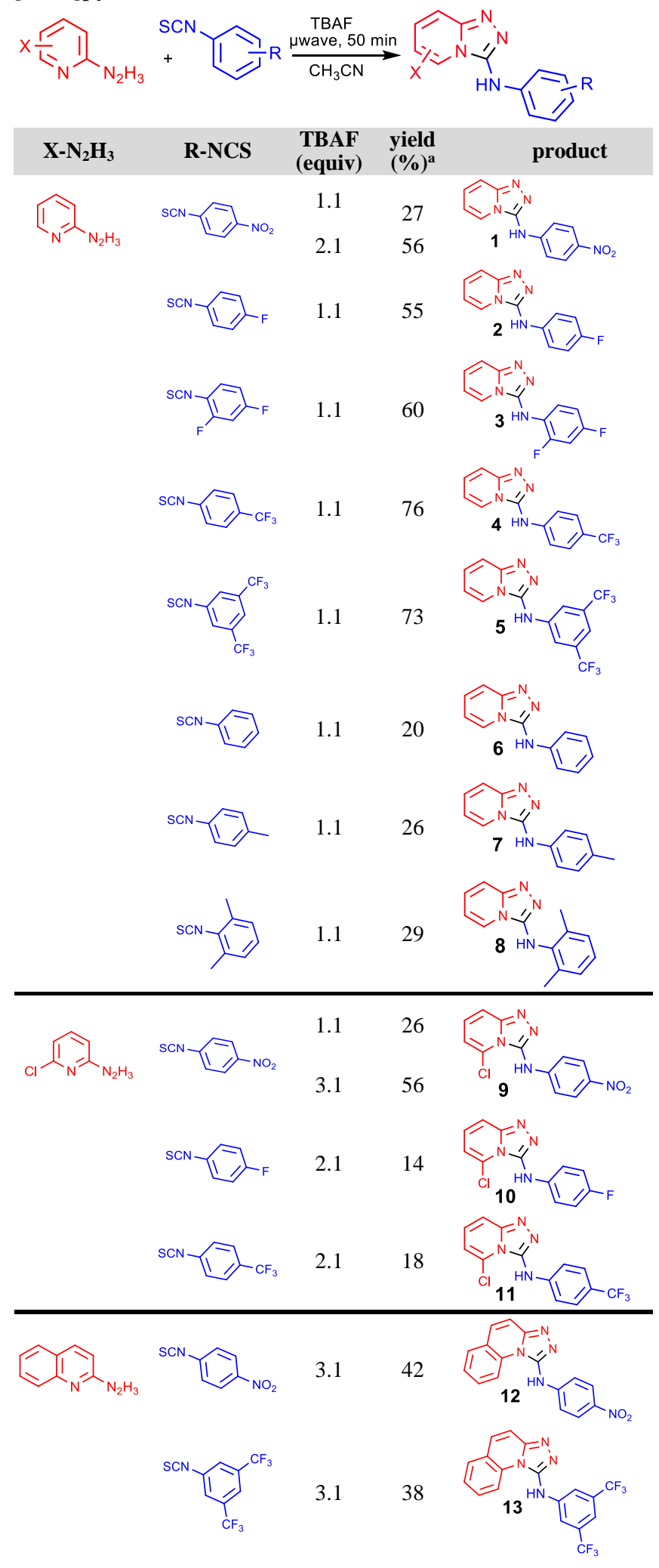

aIsolated yield. All reactions were carried out under microwave irradiation in a sealed vial. TBAF was dried over $\mathrm{P}_{2} \mathrm{O}_{5}$ under vacuum.

the triazole analogues 9, 10 and 11, Table 1. However, irrespective of the equivalents of TBAF employed, no conver- 
sion to the triazole was observed with the remaining five isothiocyanates. In fact, for all of these reactions, the corresponding thiosemicarbazides were obtained as the major products. This suggests that the nature of the substituents on both the pyridinyl and the phenyl component of the thiosemicarbazides play a critical role in the cyclisation process, with electron-withdrawing groups on the pyridine ring lowering the yield of the cyclization process. Similar to the 5-chloro derivatives, the more sterically challenging, 2-hydrazino quinoline also yielded only three triazolo pyridines. In the case of $\mathbf{1 2}$, an increase in the equivalents of TBAF from 1.1 to 3.1 resulted in an improved yield of the triazole to $38 \%$. With the $4-\mathrm{CF}_{3}$ and 3,5-di-CF $\mathrm{CF}_{3}$ triazoles being observed.

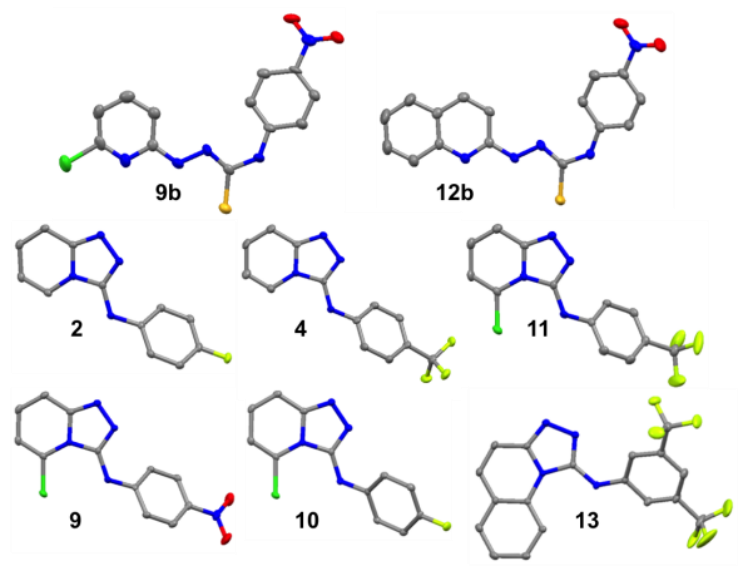

Figure 2: Solid state crystal structures.

To probe the mechanism, we investigated the reaction using ${ }^{1} \mathrm{H}$ NMR spectroscopy $\left(\left(\mathrm{CD}_{3}\right)_{2} \mathrm{SO}, 6\right.$ oo $\left.\mathrm{MHz}\right)$, where the thiosemicarbazide exhibited characteristic signals for the 'thiourea' protons, resonating between 10.2-8.1 and 10.4-8.2 ppm, depending on the nature of the aryl group. Treatment of the thiosemicarbazide with TBAF resulted in the disappearance of the thiourea proton, suggesting fluoride-mediated deprotonation is the initial step, as shown in Figure 2a. The resulting organic anion undergoes cyclisation in situ with loss of sulfur to form the desired triazole, which has a new $\mathrm{NH}$-proton appearing between 8.5-10.2 ppm, Figure $1 \mathrm{~b}$. This would suggest that the mechanism involves a) the formation of the thiosemicarbazide, b) anion recognition, and c) deprotonation of the thiourea.

Gratifyingly, this process could also be followed by X-ray crystallography, as single crystals for X-ray structure analysis were isolated and resolved for the deprotonated thiosemicarbazides, elemental sulfur, and six of the fourteen 1,2,4-triazolo pyridines products. ${ }^{24}$ Some of these structures are shown in Figure 2, clearly demonstrating the successful formation of the desired products from all of the hydrazine starting materials.

Further analysis of the synthesis, showed that additional equivalent of TBAF were required to promote the ring closing of the triazolo adducts 9 and 12. This raises the interesting possibility that TBAF may have a dual role in the reaction, functioning as both a base to deprotonate the thiosemicarbazides and as a desulfurizing agent to promote the cyclization process. In the literature, desulfurization is accomplished using toxic heavy metals oxides such as $\mathrm{Pb}_{2} \mathrm{O}_{4}, \mathrm{HgCl}_{2}, \mathrm{Hg}(\mathrm{OAc})_{2}, \mathrm{HgO}$, methyl iodide, or highly reactive acid halides such as phosgene and thionylchloride. ${ }^{20,21}$ In some reactions photo-irradiation in the presence of benzophenone promotes desulfurization. ${ }^{22}$ Because of this, additional control experiments were performed. Firstly, the synthesis of thiosemicarbazides was attempted in the absence of TBAF in order to determine if $\mathrm{F}^{-}$was necessarily required for the cyclization reaction, (Table 1, ESI). These studies found that irrespective of the substituent on the phenyl ring of the isothiocyanate, the thiosemicarbazides were only isolated as the prime product. Moreover, when the reactions were performed for 180 minutes, only thiosemicarbazide formation was observed and no cyclized product was isolated, demonstrating that the deprotonation process was an essential part of the synthesis of the desired products.

With this in mind, we also explored the use of other anions such as $\mathrm{AcO}^{-}, \mathrm{Cl}^{-}, \mathrm{H}_{2} \mathrm{PO}_{4}^{-}$and $\mathrm{OH}^{-}$. However, $\mathrm{F}^{-}$ showed by far the best conversion of the thiosemicarbazides to the triazoles. The remaining anions showed either poor conversions or hardly any at all, the order of reactivity being: $\mathrm{F}^{-}>\mathrm{AcO}^{-}>\mathrm{H}_{2} \mathrm{PO}_{4}^{-}>\mathrm{OH}^{-}>\mathrm{Cl}^{-}$. This further confirms the importance of the deprotonation step, as $\mathrm{Cl}^{-}$is not normally not considered 'good' anions for the deprotonation of ureas and thioureas. ${ }^{23}$ Hence, our results clearly evident that the $\mathrm{F}^{-}$is mediating the in situ formation of the triazolo pyridines.

Based on these results, a plausible reaction mechanism for the triazolo pyridine synthesis is illustrated in Scheme 1; the first step involving the formation of thiosemicarbazide $\mathbf{A}$. This is followed by anion recognition, in situ deprotonation of the thiosemicarbazide by $\mathrm{F}^{-}$and the generation of $\mathbf{B}$ which is evident from both NMR and Xray crystal structure analysis. Subsequent desulfurization to a carbodiimide intermediate $\mathbf{D}$ and intramolecular cyclization affords the 1,2,4- triazole $\mathbf{E}$.

In conclusion, we have successfully developed a novel, efficient and transition-metal-free, one-pot protocol for the synthesis of biologically relevant 3 -amino-[1,2,4]triazolo[4,3-a]pyridines. Control experiments provided insight into the critical role of the $\mathrm{F}^{-}$anion in the reaction as a base for deprotonation of the in situ formed thiosemicarbazide, which is the key step for the cyclization to the triazole core. We show that the substituents on both aryl starting materials have a major effect on the yield of

Scheme 1: Proposed mechanism for the formation of 1,2,4-triazolo pyridyl-3-amines.

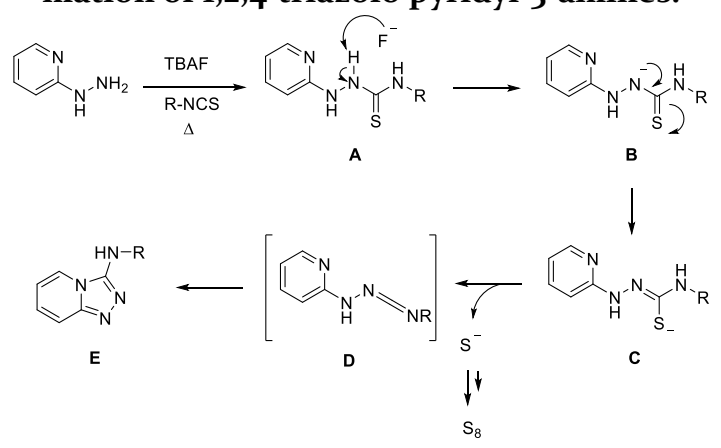


the cyclisation reaction, where EW-substituent's tend to furnish improved yields of triazoles over ED groups. This methodology can be applied and extended to variety of hydrazino pyridines to produce a broad range of $1,2,4^{-}$ triazolo pyridyl amines in an efficient manner. Further expansion of the substrate scope is currently underway in our laboratories.

\section{ASSOCIATED CONTENT}

\section{Supporting Information}

Experimental procedures; NMR characterization and HRMS analysis data of all new compounds. This material is available free of charge via the Internet at http://pubs.acs.org.

\section{AUTHOR INFORMATION}

\section{Corresponding Author}

*gunnlaut@tcd.ie, eoin.scanlan@tcd.ie.

\section{ACKNOWLEDGMENT}

Financial support from Science Foundation Ireland (SFI) for the PI 2010 (10/IN.1/B2999) and PI 2013 (13/IA/1865) grants (to TG), IRCSET Postdoctoral Fellowship (JAK), Marie Curie IEF Postdoctoral Grant (gunnlaut-ECFP7MC-NanoAgents to SB) and Ministerio of Economía y Competitividad of Spain-Postdoctoral Fellowship (MMC) is greatly acknowledged.

\section{REFERENCES}

1) Ye, Q.; Mao, W.; Zhou, Y.; Xu, L.; Li, Q.; Gao, Y.; Wang, J.; Li, C.; Xu, Y.; Xu, Y.; Liao, H.; Zhang, L.; Gao, J.; Li, J.; Pang, T. Bioorg. Med. Chem., 2015, 23, 1179; Street, L. J.; Baker, R.; Davey, W. B.; Guiblin, A. R.; Jelley, R. A.; Reeve, A. J.; Routledge, H.; Sternfeld, F.; Watt, A. P. J. Med. Chem., 1995, 38, 1799 .

2) Menet, C. J.; Fletcher, S. R.; Van Lommen, G.; Geney, R.; Blanc, J.; Smits, K.; Jouannigot, N.; Deprez, P.; van der Aar, E. M.; Clement-Lacroix, P.; Lepescheux, L.; Galien, R.; Vayssiere, B.; Nelles, L.; Christophe, T.; Brys, R.; Uhring, M.; Ciesielski, F.; Van Rompaey, L. J. Med. Chem., 2014, 57, 9323.

3) Millan, D. S.; Bunnage, M. E.; Burrows, J. L.; Butcher, K. J.; Dodd, P. G.; Evans, T. J.; Fairman, D. A.; Hughes, S. J.; Kilty, I. C.; Lemaitre, A.; Lewthwaite, R. A.; Mahnke, A.; Mathias, J. P.; Philip, J.; Smith, R. T.; Stefaniak, M. H.; Yeadon, M.; Phillips, C. J. Med. Chem., 2011, 54, 7797.

4) Li, Y.; Liang, J.; Siu, T.; Hu, E.; Rossi, M. A.; Barnett, S. F.; Defeo-Jones, D.; Jones, R. E.; Robinson, R. G.; Leander, K.; Huber, H. E.; Mittal, S.; Cosford, N.; Prasit, P. Bioorg. Med. Chem. Lett., 2009, 19, 834.

5) Dugan, B. J.; Gingrich, D. E.; Mesaros, E. F.; Milkiewicz, K. L.; Curry, M. A.; Zulli, A. L.; Dobrzanski, P.; Serdikoff, C.; Jan, M.; Angeles, T. S.; Albom, M. S.; Mason, J. L.; Aimone, L. D.; Meyer, S. L.; Huang, Z.; Wells-Knecht, K. J.; Ator, M. A.; Ruggeri, B. A.; Dorsey, B. D. J. Med. Chem., 2012, 55, 5243.

6) Natarajan, A.; Guo, Y.; Arthanari, H.; Wagner, G.; Halperin, J. A.; Chorev, M. J. Org. Chem., 2005, 70, 6362; x Kato, Y.; Ninomiya, M.; Yamaguchi, Y.; Koketsu, M. Med. Chem. Res., 2015, 24, 1180; Wang, H.; Robl, J. A.; Hamann, L. G.; Simp- kins, L.; Golla, R.; Li, Y.-X.; Seethala, R.; Zvyaga, T.; Gordon, D. A.; Li, J. J. Bioorg. Med. Chem. Lett., 2o11, 21, 4146; Mammoliti, O.; Quinton, E. M.; Loones, K. T. J.; Nguyen, A. T.; Wouters, J.; Van Lommen, G. Tetrahedron 2013, 69, 1669; Schmidt, M. A.; Qian, X. Tet. Lett., 2013, 54, 5721; Santhosh Kumar, G.; Kurumurthy, C.; Sambasiva Rao, P.; Veeraswamy, B.; Shanthan Rao, P.; Narsaiah, B. J. Heterocyclic Chem., 2015, 52,75 .

7) Comas, H.; Bernardinelli, G.; Swinnen, D. J. Org. Chem., 2009, 74, 5553 .

8) Fujita, M.; Hiyama, T. J. Am. Chem. Soc., 1984, 106, 4629; Fujita, M.; Hiyama, T. J. Org. Chem., 1988, 53, 5405;

9) Yoshizawa, M.; Klosterman, J. K.; Fujita, M. Angew. Chem. Int. Ed., 2009, 485, 3418; Kang, J., Rebek Jr., J. Nature, 1997, $385,50$.

10) Gale, P. A.; Howe, E. N.W.; Wu, X. Chem, 2016, 1, 351; Busschaert, N.; Caltagirone, C.; Van Rossom, W.; Gale, P. A. Chem. Rev., 2015, 115, 8038; Gale, P. A.; Caltagirone, C. Chem. Soc. Rev., 2015, 44, 4212.

11) Connon, S. J. Chem. Eur. J., 2006, 12, 5418; Connon, S. J. Chem. Commun., 2008, 2499.

12) Das, S.; Addis, D.; Knöpke, L. R.; Bentrup, U.; Junge, K.; Brückner, A.; Beller, M. Angew, Chem. Int. Ed.,2011, 50, 9180.

13) Gunnlaugsson, T., Kruger, P. E., Jensen, P., Pfeffer, F. M.; Hussey, G. M. Tetrahedron Lett. 2003, 44, 8909; Gunnlaugsson, T.; Kruger, P.E.; Lee, T.C.; Parkesh, R.; Pfeffer, F.M.; Hussey, G.M. Tetrahedron Lett., 2003, 44, 6575; Duke, R. M.; Gunnlaugsson, T. Tetrahedron Lett., 2007, 48, 8043.

14) Seganish, W. M.; Mowery, M. E.; Riggleman, S.; DeShong, P. Tetrahedron 2005, 61, 2117.

15) Okutani, M.; Mori, Y. J. Org. Chem., 2009, 74, 442; Souli, C.; Avlonitis, N.; Calogeropoulou, T.; Tsotinis, A.; Maksay, G.; Bíró, T.; Politi, A.; Mavromoustakos, T.; Makriyannis, A.; Reis, H.; Papadopoulos, M. J. Med. Chem., 2005, 48, 5203.

16) Pandurangan, K.; Kitchen, J. A.; Gunnlaugsson, T. Tetrahedron Lett. 2013, 54, 2770.

17) Boyle, E. M.; Comby, S.; Molloy, J. K.; Gunnlaugsson, T. J. Org. Chem., 2013, 78, 8312; Boyle, E. M.; McCabe, T.; Gunnlaugsson, T. Supramol. Chem. 2010, 22, 586.

18) Veale, E. B.; Tocci, G. M.; Pfeffer, F. M.; Kruger, P. E.; Gunnlaugsson, T. Org. Biomol. Chem., 2009, 7, 3447.

19) Gunnlaugsson, T.; Kruger, P. E.; Jensen, P.; Tierney, J.; Ali, H. D. P.; Hussey, G. M. J. Org. Chem., 2005, 70, 10875; Ali, H. D. P.; Kruger, P. E.; Gunnlaugsson, T. New J. Chem., 20o8, 32, 1153; Duke, R.M., O'Brien, J.E., McCabe, T., Gunnlaugsson, T. Org. Biomol. Chem., 20o8, 6, 4089.

2o) Senthilvelan, A.; Thirumalai, D.; Ramakrishnan, V. T. Tetrahedron 2004, 6o, 851; Williams, A.; Ibrahim, I. T. Chem. Rev. $1981,81,589-636$.

21) Kurzer, F.; Douraghi-Zadeh, K. Chem. Rev. 1967, 67, 107-152; Kato, Y.; Ninomiya, M.; Yamaguchi, Y.; Koketsu, M. Med. Chem. Res. 2015, 24, 1180.

22) Lin, H.; Shi, W.; Tian, Y.; Ma, F.; Xu, L.; Ma, J.; Hui, Y.; Xie, Z. J. Lumines., 2015, 157, 280.

23) Byrne, J.P.; Blasco, S.; Aletti, A.B., Hessman, G.; Gunnlaugsson, T. Angew. Chem. Int. Ed., 2016, 55, 8938; Pandurangan, K.; Kitchen, J. A.; Blasco, S.; Boyle, E.M.; Fitzpatrick, B.; Feeney, M.; Kruger, P.E.; Gunnlaugsson, T. Angew. Chem. Int. Ed., 2015, 54, 4566; Louise S. Evans, Philip A. Gale, Mark E. Light and Roberto Quesada Chem. Commun., 20o6, 965.

24) CCDC numbers: 2: 1525728; 4: 1524079; 9: 1524281; 9b: 1525763; 10: 1524280; 11: 1524081; 12b: 1524086; 13: 1524279 . 